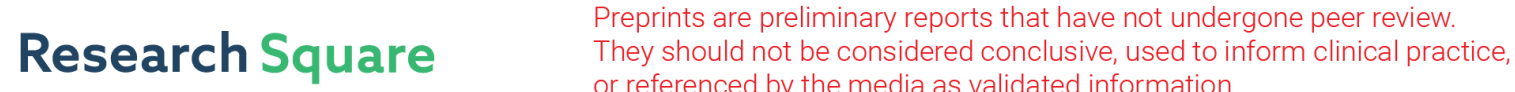 or referenced by the media as validated information. \\ The Negative Impact of Obesity on the Occurrence and Prognosis of the 2019 Novel Coronavirus (COVID-19) Disease: A Systematic Review and Meta-Analysis
}

\section{Tahereh Raeisi}

Hormozgan University of Medical Sciences

Hadis Mozaffari

University of British Columbia School of Human Kinetics: The University of British Columbia School of Kinesiology

Nazaninzahra Sepehri

Shiraz University of Medical Sciences

Mohammad Alizadeh

Mazandaran University of Medical Sciences

\section{Mina Darand}

Shahid Beheshti University of Medical Sciences Research Institute for Gastroenterology and Liver

Diseases

\section{Bahman Razi}

Tehran University of Medical Sciences

Shahab alizadeh ( $\sim$ sh_alizadeh@razi.tums.ac.ir)

TUMS: Tehran University of Medical Sciences

\section{Research}

Keywords: Obesity, COVID-19, Hospitalization, Intensive care unit, Mechanical ventilation, Death

Posted Date: October 8th, 2020

DOI: https://doi.org/10.21203/rs.3.rs-86237/v1

License: (c) (i) This work is licensed under a Creative Commons Attribution 4.0 International License. Read Full License 


\section{Abstract}

Background: the 2019 novel coronavirus (COVID-19) is an emerging pandemic, with a disease course varying from asymptomatic infection to critical disease resulting to death. Recognition of prognostic factors is essential because of its growing prevalence and high clinical costs. This meta-analysis aimed to evaluate the global prevalence of obesity in COVID-19 patients and to investigate whether obesity is a risk factor for the COVID-19, COVID-19 severity, and its poor clinical outcomes including hospitalization, intensive care unit (ICU) admission, need for mechanical ventilation, and mortality.

Methods: The study protocol was registered on to PROSPERO (CRD42020203386). A systematic search of Scopus, Medline, and Web of Sciences was conducted on June 2020, to find pertinent studies. After selection, 54 studies from 10 different countries were included in the quantitative analyses. Pooled odds ratios (OR) with $95 \%$ confidence intervals (Cls) were calculated to assess the associations.

Results: The prevalence of obesity was 33\% (95\% Cl, 30.0\%-35.0\%) among patients with COVID-19. Obesity was significantly associated with susceptibility to COVID-19 (OR=2.42, 95\% Cl: 1.58 to 3.70; moderate certainty) and COVID-19 severity (OR=1.62, 95\% Cl: 1.48 to 1.76 ; low certainty). Furthermore, obesity was a significant risk factor for hospitalization ( $\mathrm{OR}=1.75,95 \% \mathrm{Cl}: 1.47$ to 2.09 ; very low certainty), mechanical ventilation ( $\mathrm{OR}=2.24,95 \% \mathrm{Cl}: 1.70$ to 2.94 ; low certainty), intensive care unit (ICU) admission $(\mathrm{OR}=1.75,95 \% \mathrm{Cl}: 1.38$ to 2.22 ; low certainty), and death (OR=1.23, $95 \% \mathrm{Cl}: 1.06$ to 1.41 ; low certainty) in COVID-19 patients. In the subgroup analyses, these associations were supported by the majority of subgroups.

Conclusions: Obesity is associated with COVID-19 and its poor clinical outcomes. Thus, it is highly recommended to consider obesity status in prognostic scores and improvement of guidelines for the clinical care of patients with COVID-19.

\section{Background}

The 2019 novel coronavirus (COVID-19), caused by Severe Acute Respiratory Syndrome Coronavirus 2 (SARS-CoV-2), is a viral disease which first diagnosed in late 2019 in Wuhan City of Hubei Province of China, and it is spreading rapidly (1). Currently, the prevalence of COVID-19 has turned into one of the most critical public health concerns (2). Recent evidence suggests that the severity of clinical manifestations and mortality rate of the disease varies from person to person and depends on a variety of factors (3). Given this, the identification of prognostic factors related to COVID-19 and its poor clinical outcomes is urgent to distinguish populations at higher risk for the disease and to better prevention and early treatment of the disease. Since obesity is associated with a mild chronic inflammatory condition (4) and immune dysfunction (5), evidence suggests that obesity may be a risk factor (6), but the findings are still insufficient in this regard. In a single center in France, 75\% of individuals with SARS-CoV- 2 infections admitted to the intensive care unit (ICU) had a body mass index (BMI) $>30 \mathrm{~kg} / \mathrm{m} 2$. This study showed that with increasing BMI, the severity of the disease, and the proportion of patients who need mechanical 
ventilation increases but no difference in mortality rates was observed between obese and non-obese patients (7). Findings in Italy revealed that the need for intensive care and the use of a ventilator in overweight and obese patients, despite their younger age, is higher than in normal weight patients (8). A cross-sectional study in Mexico demonstrated that obesity is one of the most critical risk factors for coronavirus respiratory infection (9). In contrast, Wu J et al. did not considered a statistically significant relationship between obesity and the severity of COVID-19 (10).

Heterogeneous findings may be due to low statistical power, small sample size, unified ethnicity, and differences in age and adjustment level for covariates in individual studies. To date, some meta-analyses $(11-14)$ have attempted to summarize available evidence regarding the relation of obesity to Covid-19 outcomes. Nevertheless, the preliminary meta-analyses included small number of studies, did not comprehensively assess related clinical outcomes, did not assess the influence of potential effect modifiers such as confounder factors, age, ethnicity and study design, or were conducted on Chinese populations, and thus, were not generalizable to other populations. The current systematic review and meta-analysis study aimed to comprehensively investigate the global prevalence of obesity in patients with COVID-19 and the relation of obesity to COVID-19, COVID-19 severity, and its poor clinical outcomes including hospitalization, ICU admission, need for mechanical ventilation, and mortality.

\section{Methods}

This study was performed in a stepwise process in accordance with the guidelines of the Preferred reporting items for systematic reviews and meta-analyses (PRISMA)(15). The protocol of this study is registered in PROSPERO (ID: CRD42020203386). This article does not contain any studies with human participants performed by any of the authors.

\section{Search strategy}

An exhaustive systematic search was conducted by multiple researchers through electronic databases (Scopus, Medline, Web of Sciences) retrieving all potential publication, published up to June 2020, investigating the prevalence of obesity among COVID-19 patients or the association of obesity with the risk of COVID-19, COVID-19 severity, death, ICU admission, need for mechanical ventilation, and hospitalization due to COVID-19. The combination of key words was as follow: ("obese" OR "obesity" OR "overweight" OR "body mass index" OR "BMI" OR "adiposity" OR "adipose" OR "body size" OR "weight") AND ("COVID-19" OR "2019 novel Coronavirus" OR "2019-nCoV" OR "SARS-CoV-2" OR "coronavirus 2019 "). No restriction filter was applied for primary search and if required, Google translate was used to translate the data into English. Moreover, cross references within both eligible and review articles was carried out for feasible additional publications.

\section{Inclusion and exclusion criteria}

The retrieval publications were screened and abstracted if they met the following inclusion criteria: a) Observational studies (cohort, case-control, cross-sectional, case series); b) Studies providing sufficient 
information for the calculation of relative risk (RR) and / or odds ratio (OR), in cases which critical data were not reported in the eligible articles, we contacted authors; c) Studies reporting the prevalence of obesity in COVID-19 patients (primary outcome) and/or data on the association between obesity and following secondary outcomes: COVID-19 and COVID-19 severity (severe COVID-19 was defined based on international guidelines or hospitalization, ICU (Intensive Care Unit) admission, need for mechanical ventilator, mortality due to COVID-19 or a combination of these) (16-25). Duplicates, case reports, reviews, studies with insufficient data after contacting with authors, and abstracts were all excluded, but letters were included. It is worth mentioning that all process of data extraction was performed by two independent investigators, they verified the validity of extracted data any potential disagreements were resolved by discussion or, where necessary, by a third investigator.

\section{Data Extraction and quality assessment}

All required data were extracted conforming to the standardized extraction checklist for the following data: the first author's name, journal and year of publication, variables adjusted for, country of origin, ethnicity, mean, median or range of age, and odds ratio (OR) and corresponding confidence interval (Cl) for outcomes. Moreover, Grading of Recommendations Assessment, Development and Evaluation (GRADE) was applied to assess the overall quality of the evidence in each pooled analysis (26).

\section{Statistical analysis}

In the current study, odds ratios (ORs) were used to estimate the association of obesity with outcomes. The potential between study heterogeneity was estimated by Cochran's Q-statistic ( $P$ value $<0.10$ was considered as statistically significant) and I-squared $\left({ }^{2}\right)$ tests. Because of a remarkable evidence for heterogeneity, the random-effected model was applied $(27,28)$. In order to assessed the predefined sources of heterogeneity among included studies, subgroup analysis based on obesity severity, study

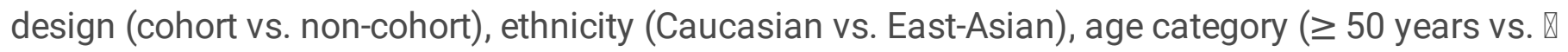
50 years), and adjustment for covariates (Adjusted vs. Non-adjusted effect size) and univariate random effects meta-regressions based on sex and age of participants were used. Additionally, in sensitivity analysis, we evaluate the conclusiveness and robustness of results by excluding each of the studies from the pooled estimate and analyzing the rest of them. This method enables the assessment of whether the

pooled estimates were affected by any individual studies. To discover the risk of publication bias and the small-study effect, Begg's funnel plots and Egger's regression test were estimated ( $P$ value $<0.05$ was considered as statistically significant) $(29,30)$. The funnel plot asymmetry was interpreted as follow: in case of no evidence of publication bias, studies with high precision (large study effects) will be located near the average line, and studies with low precision (small study effects) will be spread equally on both sides of the average line; any deviation from this shape can indicate publication bias. In the forest plot figures, the area of the squares for individual studies or diamond-shaped for overall results are inversely proportional to the variances of the log odds ratio estimates, and horizontal lines display Cls. The data analyses were carried out using STATA (version 14.0; Stata Corporation, College Station, TX) and SPSS (version 23.0; SPSS, Inc. Chicago, IL) software. 


\section{Results}

We identified 956 studies from our preliminary systematic search and 4 additional records through reference list searching. Of the 960 studies, 54 studies $(8,9,16-25,31-72)$ were eventually eligible to be included in the meta-analysis (Fig. 1); some studies reported data on $>1$ pertinent outcome. Of these, there were 52 studies reporting results on obesity prevalence among patients with COVID-19 involving a total of 504,556 cases $(8,9,16-25,31-70)$ and data regarding the secondary outcomes was reported in 43 studies $(8,9,16-25,31,32,34-38,42,43,45-55,57-61,64,67,68,70-72)$. A study by Chao et al. (73) was exclusively performed on children and thus was not included in the meta-analysis. Included publications were all observational in nature, published in 2020. The number of COVID-19 participants varied between 16 and 387,109 cases. Participants were from two ethnicities (Caucasian and East-Asian) from 10 different countries, including Mexico, United Kingdom (UK), Italy, United States of America (USA), France, China, Bolivia, Spain, Germany, and Singapore. Further characteristic of included studies are presented in Table 1.

\section{Quantitative synthesis of data}

Main pooled estimates are summarized in Table 2, and corresponding plots are provided in the Additional file 1. Meta-analysis indicated that the prevalence of obesity was $33 \%$ among individuals with COVID-19 (prevalence estimate: $33.0 \% ; 95 \% \mathrm{Cl}, 30.0-35.0 \%$ ). Moreover, not only obesity was associated with increased risk of COVID-19 (OR $=2.42,95 \% \mathrm{Cl}: 1.58$ to 3.70$)$, but it also was associated with greater risk for disease severity (OR $=1.62,95 \% \mathrm{Cl}$ : 1.48 to 1.76 ) and poor clinical outcomes of COVID-19 such as, hospitalization ( $\mathrm{OR}=1.75,95 \% \mathrm{Cl}: 1.47$ to 2.09$)$, need for mechanical ventilation ( $\mathrm{OR}=2.24,95 \% \mathrm{Cl}: 1.70$ to 2.94$), \mathrm{ICU}$ admission (OR $=1.75,95 \% \mathrm{Cl}: 1.38$ to 2.22$)$, and death (OR $=1.23,95 \% \mathrm{Cl}: 1.06$ to 1.41$)$ (Table 2). There was significant evidence for heterogeneity across studies in all analyzes (Table 2). Metaregression showed that the relationships between obesity and all outcomes were not affected by sex and age.

\section{Main findings of subgroup analysis}

Subgroup analyses have been provided in the Additional file 1. Findings showed the relationship between obesity and the occurrence COVID-19 was independent of study design, age category of participants, and the level of adjustment for covariates. Nevertheless, this association was not supported in different categories of obesity severity due to the small number analyzed studies for each category. Notably, the association of obesity with COVID-19 severity and hospitalization was supported by all subgroups. For mechanical ventilation, the relationship was significant in all subgroups except for patients with Class I/Sever obesity ( 2 studies), East-Asians ( 1 study), and patients with age $\otimes 50$ years ( 3 studies). For ICU admission, the relationship was significant in all subgroups except for patients with Class I obesity (3 studies) and East-Asians (1 study). Moreover, for death, the findings were supported in cohort studies, patients with Caucasian ethnicity, patients with age $\mathbb{8 0}$ years, and in studies with adjusted effect sizes. 


\section{Sensitivity analysis}

In the sensitivity analysis of studies on the relation of obesity to COVID-19 susceptibility and COVID-19 severity, no individual study significantly affected the pooled effect size, showing the reliability of the results. The pooled effect size ranged from 1.83 (95\% Cl: $1.44-2.33$ ) to 2.61 (95\% Cl: 1.64 to 4.14) for studies on COVID-19 (Additional file 1) and ranged from 1.83 (95\% Cl: $1.44-2.33)$ to 2.61 (95\% Cl: 1.64 to 4.14) for COVID-19 severity (Additional file 1).

\section{Publication bias}

Egger test revealed no evidence of publication bias for any of the outcomes except COVID-19 severity ( $t=$ 2.12, $p=0.04)$, hospitalization $(t=2.48, p=0.04)$, and need for mechanical ventilation $(t=6.50, p=0.001)$ (Additional file 1).

\section{Evaluation of quality of evidence according to the GRADE}

The quality of evidence for each of the outcomes is as follow: very low (COVID-19 hospitalization), low (COVID-19 severity, death, ICU admission, and need for mechanical ventilation), moderate (the risk of susceptibility to COVID-19) (Additional file 1).

\section{Discussion}

The current meta-analysis showed that the prevalence of obesity was 33\% among individuals with COVID-19. Not only was obesity associated with increased occurrence of COVID-19; but it was also associated with greater odds of developing critical conditions (e.g. hospitalization, mechanical ventilation, ICU admission), and mortality. Notably, these associations were consistently observed among Caucasians. To the best of our knowledge, this is the first study that has provided a comprehensive evaluation of both occurrence and prognosis of COVID-19 in relation to obesity.

The 33\% prevalence of obesity among patients with COVID-19 corroborates a recent review that has shown obesity is the most prevalent comorbidity among patients with severe or fatal COVID-19 (42\%) (12). Similar observations have been reported in other respiratory-related outbreaks including MERS-CoV (74), influenza (75), and SARSCoV (76). Moreover, the positive association of obesity with the occurrence and severity of COVID-19 is in line with similar reviews that only included initial studies from China (14).

In the current study obesity was associated with poor prognosis of COVID-19 by increasing the need for hospitalization, mechanical ventilation, ICU admission, and even mortality. This finding was in the line with a current systematic review that included mostly case-report, case-series, letter to editor, and comments (77). That review found that obesity was associated with the increasing prevalence of hospitalization (average of $20.4 \%$ ) and greater lethality (average of $20.4 \%$ ) in the patient with COVID-19 (77). The contribution of obesity to diseases severity and the requirement of advanced medical care in COVID-19 has been also stated in another initial review that only included 3 studies (78). Our study also further added to a meta-analysis that showed obesity is a risk factor for both ICU admission and 
mechanical ventilation requirement in COVID-19 patients (11). This is of particular importance since restricted IUC capacity has created great concern across the world. So, knowledge of relevant risk factors can help clinicians better identify and guide the high-risk populations for making the most use of available facilities to reduce morbidity and mortality outcomes of COVID-19 infection.

Although the underlying mechanism linking obesity to COVID-19 has remained to be elucidated, several potential pathways may justify this association through chronic inflammation, higher AngiotensinConverting Enzyme-2 (ACE-2) concentration, and functional restrictive capacity of the lung. Chronic inflammation is accompanied by the increased level of $C$-reactive protein, interleukin 6 , and adipokines, all of which can suppress the immune system and put the body at greater risk for the COVID-19 infection $(67,79)$. Moreover, ACE-2 receptors -responsible for facilitating COVD-19 entry into cells- can be expressed in different parts of the body including adipose tissue (80). That is, greater adiposity is equal to having more ACE-2 receptors and subsequently be more susceptible to catch COVID-19. Finally, individuals with obesity have physiological respiratory dysfunction which can increase the risk for hypoventilation (81), and thus may contribute to a worse prognosis of COVID-19.

The limitations of this study should be reported. Studies used different criteria to define obesity such that some studies define obesity based on national cut-points (BMI $>25 \mathrm{~kg} / \mathrm{m} 2)$, while others used the WHO definition of obesity (BMl $>30 \mathrm{~kg} / \mathrm{m} 2)$. Also, the included studies did not mention the detailed comorbidities of obese patients, such as diabetes and hypertension. Additionally, although we divided disease severity based on clinical symptoms, ICU care and death, the included studies still varied in their differentiation of patients' disease severity in clinical definition, with classifications of "mild, moderate, severe, and critical", "ordinary and severe/critical", "common and severe", and "non-severe and severe" disease. A high heterogeneity existed between studies; however, subgroup analyses were conducted to trace potential sources. Nonetheless, this is the first study that provided an extensive evaluation of health literature to assess the association of obesity with odds of occurrence and prognosis of COVID-19. This study brings attention to obesity as an important risk factor for COVID-19, which has dire consequences in relation to morbidity, mortality and the financial burden generated by the current pandemic. We followed a rigorous methodology as all stages were conducted by two reviewers independently including study selection, data extraction, and quality appraisal. The large sample size and extensive coverage of different regions around the world will increase the power and representativeness of the results to the whole patient population worldwide.

\section{Conclusions}

In conclusion, obesity was associated with the occurrence and poor prognosis of COVID-19. Patients with obesity need closer monitoring and earlier escalation of specific treatments to prevent severe or fatal outcomes. As waves of the pandemic are recurring, improvement of guidelines tailored to individuals with obesity is highly recommended. To provide a solid foundation for prevention and control, further investigations are required to identify the pathological mechanism underlying the association observed in our study. 


\section{Abbreviations}

COVID-19: The 2019 novel coronavirus disease; ICU: intensive care unit; OR: odds ratio; Cl: confidence interval; SARS-CoV-2: Severe Acute Respiratory Syndrome Coronavirus 2; BMI: body mass index; PRISMA: Preferred reporting items for systematic reviews and meta-analyses; RR: relative risk; GRADE: Grading of Recommendations Assessment, Development and Evaluation; ACE-2: Angiotensin-Converting Enzyme-2

\section{Declarations}

\section{Acknowledgements}

Each author acknowledges he/she has participated in the work in a substantive way and is prepared to take full responsibility for the work.

\section{Authors' contributions}

SA designed the study. MA, HM and TR searched, screened and selected the articles. NS, MD, BR and SH extracted the data from the articles. SA and HM performed data analysis and interpretation. TR drafted the manuscript. All authors contributed in writing and editing of the manuscript. SA supervised the study.

\section{Funding}

This research did not receive any specific grant from funding agencies in the public, commercial, or notfor-profit sectors.

\section{Availability of data and materials}

Data can be reached by contacting the corresponding author.

\section{Ethics approval and consent to participate}

Not applicable

\section{Consent for publication}

This is formally to submit the article entitled "The negative impact of obesity on the occurrence and prognosis of the 2019 novel coronavirus (COVID-19) disease: a systematic review and meta-analysis" prepared by the Tehran University of Medical Sciences for review and, hopefully, publication in your prestigious journal. The authors would like to advise that all authors listed have contributed to the work. All authors have agreed to submit the manuscript to Critical Care. No part of the work has been published before. There is no conflict of interest in this paper.

\section{Competing interests}

All authors declared that they have no competing interests. 


\section{Financial Disclosure}

All authors have no financial relationships relevant to this article to disclose.

\section{References}

1. Rothan HA, Byrareddy SN. The epidemiology and pathogenesis of coronavirus disease (COVID-19) outbreak. Journal of autoimmunity. 2020:102433.

2. Singhal T. A review of coronavirus disease-2019 (COVID-19). The Indian Journal of Pediatrics. 2020:1-6.

3. Zhou F, Yu T, Du R, Fan G, Liu Y, Liu Z, et al. Clinical course and risk factors for mortality of adult inpatients with COVID-19 in Wuhan, China: a retrospective cohort study. The lancet. 2020.

4. Askarpour M, Khani D, Sheikhi A, Ghaedi E, Alizadeh S. Effect of bariatric surgery on serum inflammatory factors of obese patients: a systematic review and meta-analysis. Obesity surgery. 2019:1-17.

5. Francisco V, Pino J, Campos-Cabaleiro V, Ruiz-Fernández C, Mera A, Gonzalez-Gay MA, et al. Obesity, fat mass and immune system: role for leptin. Frontiers in physiology. 2018;9:640.

6. Kassir R. Risk of COVID-19 for patients with obesity. Obesity Reviews. 2020;21(6).

7. Simonnet A, Chetboun M, Poissy J, Raverdy V, Noulette J, Duhamel A, et al. High prevalence of obesity in severe acute respiratory syndrome coronavirus-2 (SARS-CoV-2) requiring invasive mechanical ventilation [published online April 9, 2020]. Obesity (Silver Spring) doi. 2020;10.

8. Busetto L, Bettini S, Fabris R, Serra R, Dal Pra' C, Maffei P, et al. Obesity and COVID-19: an Italian snapshot. Obesity. 2020.

9. Hernández-Garduño E. Obesity is the comorbidity more strongly associated for Covid-19 in Mexico. A case-control study. Obesity Research \& Clinical Practice. 2020.

10. Wu J, Li W, Shi X, Chen Z, Jiang B, Liu J, et al. Early antiviral treatment contributes to alleviate the severity and improve the prognosis of patients with novel coronavirus disease (COVID-19). Journal of internal medicine. 2020.

11. Földi M, Farkas N, Kiss S, Zádori N, Váncsa S, Szakó L, et al. Obesity is a risk factor for developing critical condition in COVID-19 patients: A systematic review and meta-analysis. Obesity Reviews. 2020.

12. Zhou Y, Yang Q, Chi J, Dong B, Lv W, Shen L, et al. Comorbidities and the risk of severe or fatal outcomes associated with coronavirus disease 2019: A systematic review and meta-analysis. International Journal of Infectious Diseases. 2020.

13. Malik VS, Ravindra K, Attri SV, Bhadada SK, Singh M. Higher body mass index is an important risk factor in COVID-19 patients: a systematic review and meta-analysis. Environmental Science and Pollution Research. 2020:1-9. 
14. Yang J, Hu J, Zhu C. Obesity aggravates COVID-19: a systematic review and meta-analysis. Journal of medical virology. 2020.

15. Moher D, Liberati A, Tetzlaff J, Altman DG, Group P. Preferred reporting items for systematic reviews and meta-analyses: the PRISMA statement. PLoS med. 2009;6(7):e1000097.

16. Caussy C, Pattou F, Wallet F, Simon C, Chalopin S, Telliam C, et al. Prevalence of obesity among adult inpatients with COVID-19 in France. The Lancet Diabetes Endocrinology. 2020;8(7):562-4.

17. Khoury R, Bernstein PS, Debolt C, Stone J, Sutton DM, Simpson LL, et al. Characteristics and Outcomes of 241 Births to Women With Severe Acute Respiratory Syndrome Coronavirus 2 (SARSCoV-2) Infection at Five New York City Medical Centers. Obstetrics Gynecology. 2020;136(2):273-82.

18. Huang R, Zhu L, Xue L, Liu L, Yan X, Wang J, et al. Clinical findings of patients with coronavirus disease 2019 in Jiangsu province, China: A retrospective, multi-center study. PLOS Neglected Tropical Diseases. 2020;14(5):e0008280.

19. Gao F, Zheng KI, Wang X-B, Sun Q-F, Pan K-H, Wang T-Y, et al. Obesity is a risk factor for greater COVID-19 severity. Diabetes Care. 2020.

20. Zheng KI, Gao F, Wang X-B, Sun Q-F, Pan K-H, Wang T-Y, et al. Obesity as a risk factor for greater severity of COVID-19 in patients with metabolic associated fatty liver disease. Metabolism. 2020:154244.

21. Cai Q, Chen F, Wang T, Luo F, Liu X, Wu Q, et al. Obesity and COVID-19 severity in a designated hospital in Shenzhen, China. Diabetes Care. 2020.

22. Petrilli CM, Jones SA, Yang J, Rajagopalan H, O'Donnell L, Chernyak Y, et al. Factors associated with hospital admission and critical illness among 5279 people with coronavirus disease 2019 in New York City: prospective cohort study. bmj. 2020;369.

23. Kayem G, Alessandrini V, Azria E, Blanc J, Bohec C, Bornes M, et al. A snapshot of the Covid-19 pandemic among pregnant women in France. Journal of Gynecology Obstetrics and Human Reproduction. 2020:101826.

24. Buckner FS, McCulloch DJ, Atluri V, Blain M, McGuffin SA, Nalla AK, et al. Clinical Features and Outcomes of 105 Hospitalized patients with COVID-19 in Seattle, Washington. Clinical Infectious Diseases. 2020.

25. Docherty AB, Harrison EM, Green CA, Hardwick HE, Pius R, Norman L, et al. Features of 20133 UK patients in hospital with covid-19 using the ISARIC WHO Clinical Characterisation Protocol: prospective observational cohort study. bmj. 2020;369.

26. Group GW. Grading of recommendations assessment, development and evaluation (GRADE). 2012.

27. DerSimonian R, Laird N. Meta-analysis in clinical trials. Controlled clinical trials. 1986;7(3):177-88.

28. Mantel N, Haenszel W. Statistical aspects of the analysis of data from retrospective studies of disease. Journal of the national cancer institute. 1959;22(4):719-48.

29. Begg CB, Mazumdar M. Operating characteristics of a rank correlation test for publication bias. Biometrics. 1994:1088 - 101. 
30. Deeks JJ, Macaskill P, Irwig L. The performance of tests of publication bias and other sample size effects in systematic reviews of diagnostic test accuracy was assessed. J Clin Epidemiol. 2005;58(9):882-93.

31. Argenziano MG, Bruce SL, Slater CL, Tiao JR, Baldwin MR, Barr RG, et al. Characterization and clinical course of 1000 patients with coronavirus disease 2019 in New York: retrospective case series. bmj. 2020;369.

32. Auld S, Caridi-Scheible M, Blum JM, Robichaux CJ, Kraft CS, Jacob JT, et al. ICU and ventilator mortality among critically ill adults with COVID-19. medRxiv. 2020.

33. Barrasa H, Rello J, Tejada S, Martín A, Balziskueta G, Vinuesa C, et al. SARS-CoV-2 in Spanish intensive care: early experience with 15-day survival in Vitoria. Anaesthesia Critical Care \& Pain Medicine. 2020.

34. Bello-Chavolla OY, Bahena-Lopez JP, Antonio-Villa NE, Vargas-Vázquez A, González-Díaz A, MárquezSalinas A, et al. Predicting mortality due to SARS-CoV-2: A mechanistic score relating obesity and diabetes to COVID-19 outcomes in Mexico. medRxiv. 2020.

35. Cariou B, Hadjadj S, Wargny M, Pichelin M, Al-Salameh A, Allix I, et al. Phenotypic characteristics and prognosis of inpatients with COVID-19 and diabetes: the CORONADO study. Diabetologia. 2020:116.

36. Crespo M, José Pérez-Sáez M, Redondo-Pachón D, Llinàs-Mallol L, Montero MM, Villar J, et al. COVID-19 in elderly kidney transplant recipients. American Journal of Transplantation. 2020.

37. Cummings MJ, Baldwin MR, Abrams D, Jacobson SD, Meyer BJ, Balough EM, et al. Epidemiology, clinical course, and outcomes of critically ill adults with COVID-19 in New York City: a prospective cohort study. The Lancet. 2020.

38. de Lusignan S, Dorward J, Correa A, Jones N, Akinyemi O, Amirthalingam G, et al. Risk factors for SARS-CoV-2 among patients in the Oxford Royal College of General Practitioners Research and Surveillance Centre primary care network: a cross-sectional study. The Lancet Infectious Diseases. 2020.

39. Di Bella S, Cesareo R, De Cristofaro P, Palermo A, Sanson G, Roman-Pognuz E, et al. Neck circumference as reliable predictor of mechanical ventilation support in adult inpatients with COVID19: a multicentric prospective evaluation. Diabetes/Metabolism Research and Reviews. 2020:e3354.

40. Dreher M, Kersten A, Bickenbach J, Balfanz P, Hartmann B, Cornelissen C, et al. The characteristics of 50 hospitalized COVID-19 patients with and without ARDS. Deutsches Ärzteblatt International. 2020;117(10):271.

41. Edler C, Schröder AS, Aepfelbacher M, Fitzek A, Heinemann A, Heinrich F, et al. Dying with SARS-CoV2 infection-an autopsy study of the first consecutive 80 cases in Hamburg, Germany. International Journal of Legal Medicine. 2020:1.

42. Escalera-Antezana JP, Lizon-Ferrufino NF, Maldonado-Alanoca A, Alarcón-De-la-Vega G, AlvaradoArnez LE, Balderrama-Saavedra MA, et al. Risk factors for mortality in patients with Coronavirus 
Disease 2019 (COVID-19) in Bolivia: An analysis of the first 107 confirmed cases. Le Infezioni in Medicina. 2020;28(2):238-42.

43. Fasano A, Cereda E, Barichella M, Cassani E, Ferri V, Zecchinelli AL, et al. COVID-19 in Parkinson's Disease Patients Living in Lombardy, Italy. Movement Disorders. 2020.

44. Garg S. Hospitalization rates and characteristics of patients hospitalized with laboratory-confirmed coronavirus disease 2019-COVID-NET, 14 States, March 1-30, 2020. MMWR Morbidity and mortality weekly report. 2020;69.

45. Giacomelli A, Ridolfo AL, Milazzo L, Oreni L, Bernacchia D, Siano M, et al. 30-day mortality in patients hospitalized with COVID-19 during the first wave of the Italian epidemic: a prospective cohort study. Pharmacological Research. 2020:104931.

46. Hajifathalian K, Kumar S, Newberry C, Shah S, Fortune B, Krisko T, et al. Obesity is associated with worse outcomes in COVID-19: Analysis of Early Data From New York City. Obesity. 2020.

47. Hamer M, Kivimäki M, Gale CR, Batty GD. Lifestyle risk factors, inflammatory mechanisms, and COVID-19 hospitalization: A community-based cohort study of 387,109 adults in UK. Brain, Behavior, and Immunity. 2020.

48. Hu L, Chen S, Fu Y, Gao Z, Long H, Wang J-m, et al. Risk factors associated with clinical outcomes in 323 COVID-19 hospitalized patients in Wuhan, China. Clinical infectious diseases. 2020.

49. Hur K, Price CP, Gray EL, Gulati RK, Maksimoski M, Racette SD, et al. Factors Associated With Intubation and Prolonged Intubation in Hospitalized Patients With COVID-19. Otolaryngology-Head and Neck Surgery. 2020.

50. Kalligeros M, Shehadeh F, Mylona EK, Benitez G, Beckwith CG, Chan PA, et al. Association of obesity with disease severity among patients with coronavirus disease 2019. Obesity. 2020;28(7):1200-4.

51. Klang E, Kassim G, Soffer S, Freeman R, Levin MA, Reich DL. Morbid Obesity as an Independent Risk Factor for COVID-19 Mortality in Hospitalized Patients Younger than 50. Obesity. 2020.

52. Knight M, Bunch K, Vousden N, Morris E, Simpson N, Gale C, et al. Characteristics and outcomes of pregnant women admitted to hospital with confirmed SARS-CoV-2 infection in UK: national population based cohort study. bmj. 2020;369.

53. Kuderer NM, Choueiri TK, Shah DP, Shyr Y, Rubinstein SM, Rivera DR, et al. Clinical impact of COVID19 on patients with cancer (CCC19): a cohort study. The Lancet. 2020.

54. Lemyze M, Courageux N, Maladobry T, Arumadura C, Pauquet P, Orfi A, et al. Implications of Obesity for the Management of Severe Coronavirus Disease 2019 Pneumonia. Critical Care Medicine. 2020.

55. Lighter J, Phillips M, Hochman S, Sterling S, Johnson D, Francois F, et al. Obesity in patients younger than 60 years is a risk factor for Covid-19 hospital admission. Clinical Infectious Diseases. 2020.

56. Lokken EM, Walker CL, Delaney S, Kachikis A, Kretzer NM, Erickson A, et al. Clinical Characteristics of 46 Pregnant Women with a SARS-CoV-2 Infection in Washington State. American Journal of Obstetrics and Gynecology. 2020. 
57. Mani VR, Kalabin A, Valdivieso SC, Murray-Ramcharan M, Donaldson B. At the epicenter of the American Coronavirus outbreak-New York inner city hospital COVID-19 experience and current data: a retrospective analysis. Journal of Medical Internet Research. 2020.

58. Memtsoudis SG, Ivascu NS, Pryor KO, Goldstein PA. Obesity as a risk factor for poor outcome in COVID-19-induced lung injury: the potential role of undiagnosed obstructive sleep apnoea. BJA: British Journal of Anaesthesia; 2020.

59. Moriconi D, Masi S, Rebelos E, Virdis A, Manca ML, De Marco S, et al. Obesity prolongs the hospital stay in patients affected by COVID-19, and may impact on SARS-COV-2 shedding. Obesity Research \& Clinical Practice. 2020.

60. Ong SWX, Young BE, Leo Y-S, Lye DC. Association of higher body mass index (BMI) with severe coronavirus disease 2019 (COVID-19) in younger patients. Clinical infectious diseases: an official publication of the Infectious Diseases Society of America. 2020.

61. Palaiodimos L, Kokkinidis DG, Li W, Karamanis D, Ognibene J, Arora S, et al. Severe obesity, increasing age and male sex are independently associated with worse in-hospital outcomes, and higher in-hospital mortality, in a cohort of patients with COVID-19 in the Bronx, New York. Metabolism. 2020;108:154262.

62. Palmieri L, Vanacore N, Donfrancesco C, Lo Noce C, Canevelli M, Punzo O, et al. Clinical Characteristics of Hospitalized Individuals Dying with COVID-19 by Age Group in Italy. The Journals of Gerontology: Series A; 2020.

63. Piva S, Filippini M, Turla F, Catteneo S, Margola A, De Fulviis S, et al. Clinical presentation and initial management critically ill patients with severe acute respiratory syndrome coronavirus 2 (SARS-CoV2) infection in Brescia, Italy. Journal of Critical Care. 2020.

64. Price-Haywood EG, Burton J, Fort D, Seoane L. Hospitalization and mortality among black patients and white patients with Covid-19. New England Journal of Medicine. 2020.

65. Richardson S, Hirsch JS, Narasimhan M, Crawford JM, McGinn T, Davidson KW, et al. Presenting characteristics, comorbidities, and outcomes among 5700 patients hospitalized with COVID-19 in the New York City area. Jama. 2020.

66. Sabatino J, Ferrero P, Chessa M, Bianco F, Ciliberti P, Secinaro A, et al. COVID-19 and Congenital Heart Disease: Results from a Nationwide Survey. Journal of Clinical Medicine. 2020;9(6):1774.

67. Simonnet A, Chetboun M, Poissy J, Raverdy V, Noulette J, Duhamel A, et al. High prevalence of obesity in severe acute respiratory syndrome coronavirus-2 (SARS-CoV-2) requiring invasive mechanical ventilation. Obesity. 2020.

68. Suleyman G, Fadel RA, Malette KM, Hammond C, Abdulla H, Entz A, et al. Clinical characteristics and morbidity associated with coronavirus disease 2019 in a series of patients in metropolitan detroit. JAMA network open. 2020;3(6):e2012270-e.

69. Tatum D, Taghavi S, Houghton A, Stover J, Toraih E, Duchesne J. Neutrophil-to-lymphocyte ratio and outcomes in Louisiana COVID-19 patients. Shock (Augusta, Ga). 2020. 
70. Toussie D, Voutsinas N, Finkelstein M, Cedillo MA, Manna S, Maron SZ, et al. Clinical and chest radiography features determine patient outcomes in young and middle age adults with COVID-19. Radiology. 2020:201754.

71. Yates T, Razieh C, Zaccardi F, Davies MJ, Khunti K. Obesity and risk of COVID-19: analysis of UK Biobank. Primary Care Diabetes. 2020.

72. Zhang F, Xiong Y, Wei Y, Hu Y, Wang F, Li G, et al. Obesity predisposes to the risk of higher mortality in young COVID-19 patients. Journal of Medical Virology. 2020.

73. Chao JY, Derespina KR, Herold BC, Goldman DL, Aldrich M, Weingarten J, et al. Clinical characteristics and outcomes of hospitalized and critically ill children and adolescents with coronavirus disease 2019 (COVID-19) at a tertiary care medical center in New York City. The Journal of pediatrics. 2020.

74. Badawi A, Ryoo SG. Prevalence of comorbidities in the Middle East respiratory syndrome coronavirus (MERS-CoV): a systematic review and meta-analysis. International Journal of Infectious Diseases. 2016;49:129-33.

75. Mertz D, Kim TH, Johnstone J, Lam P-P, Kuster SP, Fadel SA, et al. Populations at risk for severe or complicated influenza illness: systematic review and meta-analysis. Bmj. 2013;347:f5061.

76. Chan J, Ng C, Chan Y, Mok T, Lee S, Chu S, et al. Short term outcome and risk factors for adverse clinical outcomes in adults with severe acute respiratory syndrome (SARS). Thorax. 2003;58(8):6869.

77. de Siqueira JVV, Almeida LG, Zica BO, Brum IB, Barceló A, de Siqueira Galil AG. Impact of obesity on hospitalizations and mortality, due to COVID-19: A systematic review. Obesity Research \& Clinical Practice. 2020.

78. Tamara A, Tahapary DL. Obesity as a predictor for a poor prognosis of COVID-19: A systematic review. Diabetes \& Metabolic Syndrome: Clinical Research \& Reviews; 2020.

79. de Heredia FP, Gómez-Martínez S, Marcos A. Obesity, inflammation and the immune system. Proceedings of the Nutrition Society. 2012;71(2):332-8.

80. Jia X, Yin C, Lu S, Chen Y, Liu Q, Bai J, et al. Two things about COVID-19 might need attention. 2020.

81. Watson R, Pride NB, Thomas EL, Fitzpatrick J, Durighel G, McCarthy J, et al. Reduction of total lung capacity in obese men: comparison of total intrathoracic and gas volumes. J Appl Physiol. 2010;108(6):1605-12.

\section{Tables}

Due to technical limitations, table $1 \& 2$ is only available as a download in the Supplemental Files section.

\section{Figures}




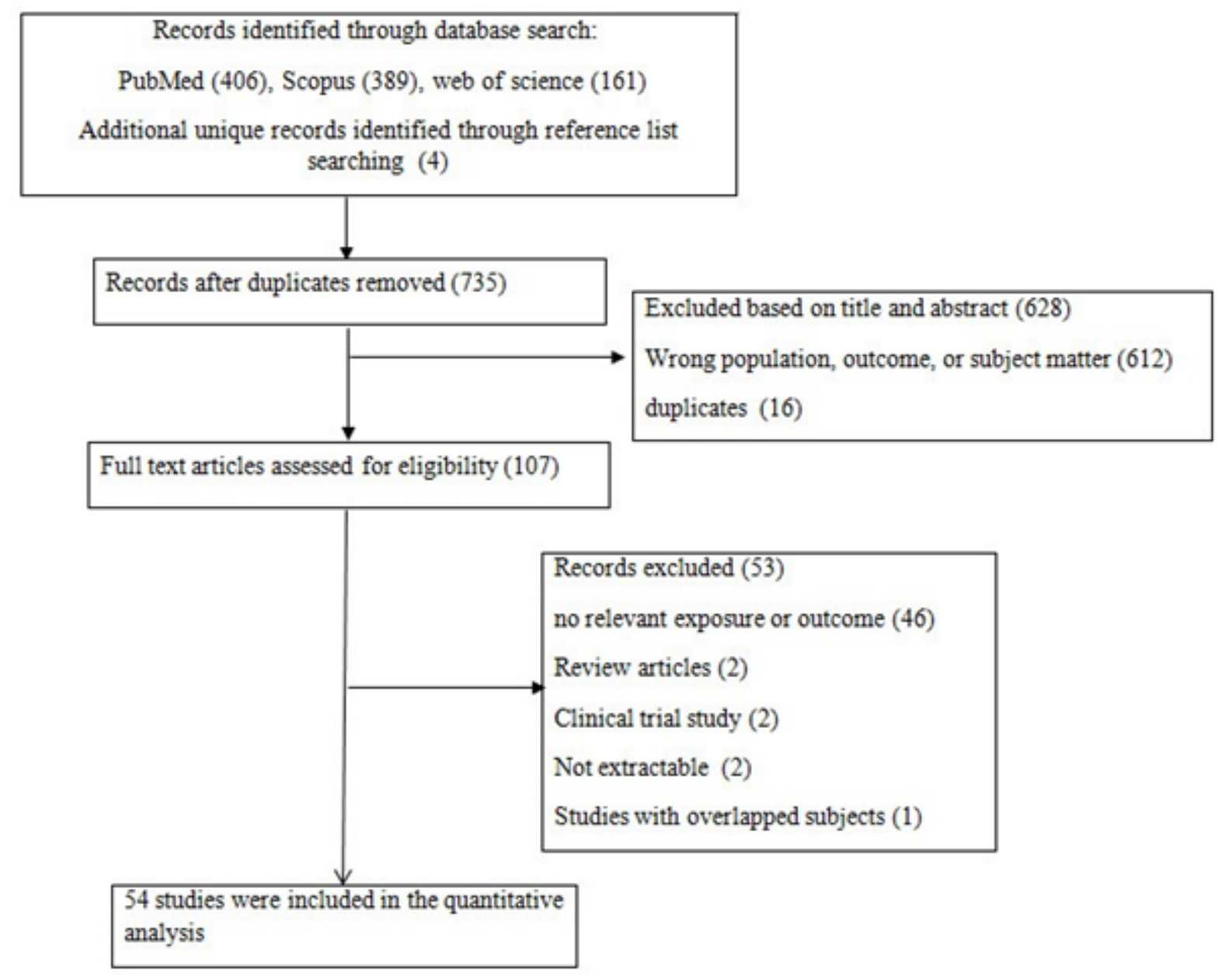

\section{Figure 1}

Flow diagram of the study

\section{Supplementary Files}

This is a list of supplementary files associated with this preprint. Click to download.

- Additionalfile1.docx

- Tables.docx 